\title{
A "nova" história intelectual: Debate virtual sobre a realidade de um mito.
} Affonso Celso Thomaz Pereira*

PALTI, Elías José. Mito y realidad de la 'cultura política latinoamericana'. Debates en Iberoideas". Buenos Aires: Prometeo, 2010. 272, p.

A primeira coisa que deve ser dita sobre a obra Mito y realidad de la "cultura política latinoamericana”. Debates en Iberoideas é que ela representa uma novidade promissora no campo editorial historiográfico em seu aspecto formal, extremamente caro aos historiadores, que é o do efetivo debate de ideias. A obra, organizada pelo historiador argentino Elías José Palti ${ }^{1}$, é resultado de uma consulta ao foro virtual Iberdoideas $^{2}$, composto por um grupo de pesquisadores, estudantes e professores, de distintas origens geográficas e acadêmicas, ligados à história dos conceitos, à história intelectual e à história das linguagens políticas. A proposta do debate foi "pôr em discussão a ideia da existência de uma "cultura política latino-americana" (PALTI: 2010, p.10), para tanto se selecionou uma série de textos recentes pertinentes ao tema, publicados no sítio do foro, entre 2006 e 2008, que foram submetidos ao escrutínio virtual dos membros do grupo na América Latina, nos Estados Unidos e na Europa.

Cada um dos oito artigos que compõem o volume é acompanhado por uma série de comentários, respostas e tréplicas, o que evidencia o caráter dialógico da obra, a pluralidade de matrizes intelectuais em jogo e a vitalidade de um debate historiográfico, ainda recente nas praias latino-americanas.

Elías Palti aponta, na introdução ao volume, que a noção de "cultura política" foi forjada nos anos 1960 pelos cientistas políticos Gabriel Almond e Sydney Verba ${ }^{3}$ que, partindo dos postulados da sociologia funcionalista de Talcott Parsons, definiram três formas de interações sociais -de paróquia, de súdito e de participação - com a intenção de determinar qual destes tipos de cultura política era mais afim com os valores democráticos (o que, tautologicamente, resultaria ser a cultura de participação, identificada com as democracias dos países capitalistas avançados).

\footnotetext{
Doutorando História Social pela Universidade de São Paulo. E-mail: affonso.thomaz@usp.br.

Professor na Universidad de Quilmes, é também editor da revista Prismas de história intelectual, um dos mais importantes fóruns de debate em história das ideias no espaço latino-americano.

Disponível em: http://foroiberoideas.cervantesvirtual.com/.

ALMOND, Gabriel; VERBA, Sydney. The civic culture. Political attitudes and democracy in five nations. Princeton: Princeton University Press, 1963.
}

Revista Eletrônica da ANPHLAC, n.14, p. 319-324, ene./jun. 2013. http://revista.anphlac.org.br/index.php/revista 
Na historiografia latino-americana o tópico da "cultura política", com seus teleologismos e tautologias, possui um longo e variado caminho percorrido, representado pela busca de um ethos, uma essência, que distinguisse as práticas sociais e as ideias no subcontinente. Esta trajetória, segundo Palti, remonta aos anos 1940 e a obra do mexicano Leopoldo Zea, para quem o interesse filosófico no pensamento latinoamericano só se justificaria pelo que há de negativo, de erro, de desvio em relação à matriz europeia, uma vez que não há, positivamente, um pensamento original local. Consolidar-se-ia, a partir daí, uma vigorosa escola interpretativa que parte dos topoi opositivos binários, como conceitos estáticos e tipos ideais, logos/pathos, moderno/arcaico, liberal/conservador, razão/tradição para explicar o desenvolvimento das ideias e práticas sociais na periférica América Latina em função da matriz conceitual e moral europeia e norte-americana.

A ideia de um tipo-ideal operando na construção de um objeto pode ser muito bem observada no texto de João Feres Júnior, que analisa o uso do termo de Latin America nos Estados Unidos, partindo da pergunta: "o que ocorre com o conceito [de Latin America] quando se converte em objeto de estudo das ciências sociais" (PALTI: 2010, p. 28). Através de cartuns e de pesquisas de opinião norte-americanos, entre fins do século 19 até a década de 1960, o autor percebe que Latin America em seu uso no senso comum foi definida como o outro da auto-imagem de "América" segundo uma tripla oposição, cultural, temporal e racial, em que ficam marcadas as características atribuídas aos latinos americanos e à América Latina: católica, particularista e autoritária; primitiva, infantil e atrasada; e negra, mestiça e indígena.

Estas imagens do senso comum foram incorporadas no campo acadêmico junto da perspectiva governamental dos programas políticos, econômicos e culturais dos anos 1950 e 60 para a América Latina. Deste modo, as teorias da modernização econômica e da estabilidade política, criadas pelo discurso oficial norte-americano para a América Latina, redundaram na produção de uma historiografia que difundia uma alteridade radical ligada a uma paralisia temporal e uma incapacidade histórica para a modernidade. Por fim, Feres Júnior aponta que os manuais mais atuais dos Latin America studies, como o best-seller Modern Latin America organizado por Thomas Skidmore e Peter Smith em 2001, recaem na mesma retórica, ao asseverar, por exemplo, que entre os latinoamericanos, "a conquista deu início a uma tradição de violência" ou em outra parte "en Latinoamérica el pasado colonial no es un recuerdo nostálgico, sino uma realidad cruel" (PALTI: 2010, p. 34).

Revista Eletrônica da ANPHLAC, n.14, p. 319-324, ene./jun. 2013. http://revista.anphlac.org.br/index.php/revista 
Em "El paradigma y la disputa. Notas para una genealogía de la cuestión liberal en México y América Hispánica", o professor da Universidade de Florença, Antonio Annino, parte da hipótese de que a permanência ao longo de dois séculos de polêmicas e dilemas em torno do liberalismo oitocentista na América Latina sugere "que estamos diante de algo peculiar e distinto dos processo políticos que plasmaram a história do liberalismo" (PALTI: 2010, p.48). Para o autor, o liberalismo, ao longo do século XIX, tornara-se uma verdade evidente, um critério de análise política: através de conceitos como "Direito", "Liberdade" ou "Representação", o liberalismo incorporava o passado como negação e exigia para si um futuro aberto a suas determinações. Haveria, então, um descolamento da investigação sobre as condições históricas que forjaram o liberalismo na América do debate sobre o tema, que se autonomizaria numa disputa sobre o discurso do liberalismo hoje.

O artigo de Elias José Palti retoma parte do conteúdo expresso na introdução, e que se alinha com o quadro geral de preocupações deste pesquisador: como pensar uma nova história intelectual para a América Latina diante da existência de uma longa e forte tradição de pensamento que consolidou tipos ideais e substratos culturais como ferramentas indiscutíveis.

Analisando "El positivismo en México", de Leopoldo Zea, Palti afirma que do “intento de historicizar as ideias" (PALTI: 2010, p. 85), para situá-las em seu contexto particular, resultaram os desvios, os erros e as refrações locais do pensamento "original", que acabariam por constituir o desenho básico das análises fundadas no esquema de "modelo" e "desvio". O sucesso deste esquema deixaria como herança para a escrita da história um tipo de pressuposto impensado, de validez metodológica óbvia, já não mais questionado nas pesquisas históricas, segundo o qual as ideias liberais na América Latina estariam sempre em déficit em relação a Europa e EUA, ou como nas palavras de Roberto Schwarcz, estariam "fora do lugar".

Nos anos 1970, inicia-se um processo de revisionismo desta historiografia, encabeçado por Charles Hale, que buscava desprovincializar o liberalismo político latino-americano, ao apontar que a mescla entre ideias liberais e conservadoras não seria estranha mesma à tradição europeia marcada por um liberalismo francês e outro inglês. Todavia, Hale insiste na existência de um substrato histórico, de uma cultura política ahistórica, ao argumentar que na América Latina "as ideias liberais se aplicaram (...) em um ambiente que lhes era refratário e hostil” (PALTI: 2010, p. 95). 
A mudança de perspectiva na historiografia recente é o tema do texto de Ana Carolina Ibarra, que avança sobre os aportes latino-americanos ao chamado "girolingüístico" na análise do período de independência. Segundo Ibarra, a revisão da historiografia no sentido de apreender discursos e motivações dos envolvidos na independência contradiz, muitas vezes, as grandes teorias ao contrapor os modelos liberais europeus à complexidade das práticas e discursos políticos vividos no período pós-independência.

Morelos, no México, por exemplo, diz que é necessário "conservar a independência" e "restabelecer no trono o amado rei". A não ser que se perscrute o idioma do direito natural, utilizado pelos atores naquele momento, e os dilemas aos quais estavam expostos, cairemos nas leituras maniqueístas em que o liberalismo latino é híbrido, é um liberalismo-conservador ou que nunca existiu. A pesquisadora mexicana ressalta que, mercê de uma nova historiografia representada, segundo ela, por Elias Palti e Alfredo Ávila, e preocupada com o uso da linguagem por seus atores sociais em seus contextos específicos, tem-se observado importantes avanços nos estudos sobre o processo de independência latino-americano, nos quais elementos aparentemente contraditórios e díspares são encarados como componentes de um universo político e linguístico essencialmente tenso e ambíguo.

Esta nova historiografia -representada justamente por membros do grupo Iberoideas, como Javier Sebástian Fernández e Elias Palti-, agora, enfrentará dura crítica no artigo de Roberto Breña ${ }^{4}$, especialmente pelo uso insistente e exagerado dos conceitos "liberalismo" e "liberal" para tratar da história da América pós-independente.

A existência de princípios liberais na linguagem comum do período não bastaria para caracterizar, "sem poréns", os processos históricos de liberais. Breña também realiza um recorrido da história das ideias no subcontinente, segundo a qual, as interpretações clássicas opunham o liberalismo disseminado dos americanos ao reacionarismo/absolutismo metropolitano; já os enfoques culturalistas e dependentistas inverteriam a chave e o liberalismo passaria a ser visto como inviável nestas terras, as ideias liberais estariam realmente "fora de seu lugar". Agora, aponta o autor de "El primer liberalismo español", a historiografia move-se novamente no sentido de fazer do liberalismo um ator protagonista, e dos demais personagens mera cenografia, pois, em reação à perspectiva da impossibilidade do liberalismo, passou-se a ver liberalismo em

4 Talvez valha ressaltar que seu texto ocupa 11 páginas e os comentários 19.

Revista Eletrônica da ANPHLAC, n.14, p. 319-324, ene./jun. 2013. http://revista.anphlac.org.br/index.php/revista 
toda parte, uma vez que se outorgou à linguagem uma capacidade transformadora e instituidora da realidade que lhe parece excessiva, pois "demasiado distantes das práticas políticas concretas" (PALTI: 2010, p. 165).

Érika Pani, em seu artigo “¿La voz de la Nación? Los dilemas de la representación política", ao refletir sobre a tradicional historiografia conclui que "a obsessão latino-americana por rastrear influências e localizar modelos tem talvez nublado o inusitado do experimento pós-revolucionário (...) a reinvenção da legitimidade política, a reestruturação da comunidade" (PALTI: 2010, p. 189). Independentemente dos rótulos que se queiram dar, alerta a pesquisadora, o fato é que no período de independência os homens encontravam-se diante de desafios inesperados e inéditos. A quebra do poder monárquico impôs que se refizesse a base de autoridade metafísica em uma legitimidade fundada no poder público e que se (re)criassem laços sociais que constituem uma sociedade política.

A ideia da necessidade da criação e invenção dos homens latino-americanos diante das novidades trazidas pela independência volta a aparecer no artigo de Hilda Sabato, que trata do caráter experimental do processo de independência e da formação das novas repúblicas na América Hispânica a partir de dois eixos que ela considera centrais para o desenvolvimento da reflexão sobre o liberalismo na América: a representação política e a opinião pública.

Recusando a historiografia tradicional, segundo a qual haveria uma incompatibilidade entre os princípios liberais e a prática social no Novo Mundo, Sábato afirma que a hispanoamérica pós-independência logo "se converteu em um vasto laboratório de ensaios em torno do sufrágio e das eleições" (PALTI: 2010, p. 214). Nas novas repúblicas, as práticas eleitorais, os comícios e os partidos políticos, por um lado, e a imprensa e os espaços públicos de sociabilidade política, por outro, confirmavam a realidade de uma nova experiência não apenas na América, mas também para a Europa.

No último artigo, Marcela Ternavasio parte de uma crítica à ideia de causalidade do caudilhismo como traço cultural da sociedade platina que marcaria sua inadequação ao liberalismo político. $\mathrm{O}$ fato de o tema da limitação do poder não ter impedido a instauração de regimes autoritários não deve deslegitimar a ideia e as discussões mesmas, tampouco reforçar uma possível cultura política autoritária que emerge naturalmente de quando em vez. 
Limitar o poder, no caso da Região do Prata, significou ora "pôr freios às intenções da península”, ora recusar os avanços de Buenos Aires sobre as províncias e, ainda, a resistência à ditadura imposta por Manuel de Rosas.

A conclusão de Ternavasio encaminha-se no sentido de que os dilemas e paradoxos do liberalismo podiam ser vistos com mais nitidez na América Latina por ser aqui, neste momento, o laboratório de ensaios republicanos do mundo -como defendeu Hilda Sabato. Os termos aos quais chega a autora poderiam bem ser compartilhados por grande parte dos autores e comentadores do livro, mas não como unanimidade. Pôr atenção nos dilemas, na linguagem e nas práticas dos atores sociais, antes de subsumilos às doutrinas e modelos pré-estabelecidos.

Virtude de um trabalho intelectualmente comprometido, as disputas teóricas e historiográficas acerca da história das ideias na América Latina presentes na obra deixam inequívoco o esforço dos debatedores e do organizador da obra em apresentar o resultado de uma empresa intelectual séria e profícua.

Recebida em: agosto de 2012 e aprovada em: outubro de 2012.

Revista Eletrônica da ANPHLAC, n.14, p. 319-324, ene./jun. 2013. http://revista.anphlac.org.br/index.php/revista 